Check for updates

Cite this: RSC Adv., 2018, 8, 5212

Received 14th September 2017 Accepted 19th January 2018

DOI: $10.1039 / c 7 r a 10239 a$

rsc.li/rsc-advances

\section{New highly hydrated cellulose microfibrils with a tendril helical morphology extracted from agro- waste material: application to removal of dyes from waste water}

\author{
M. El Achaby, (DD *a N. Fayoud, ${ }^{a}$ M. C. Figueroa-Espinoza, ${ }^{b}$ H. Ben youcef ${ }^{a}$ \\ and A. Aboulkas ${ }^{\mathrm{C}}$
}

Cocoa bean shells (CBS) are a by-product of the cocoa bean processing industry. They represent 1220 wt\% of dry cocoa beans, after having been separated from these by a roasting process. CBS often end up as a waste product which contains around $34 \mathrm{wt} \%$ of cellulose. The transformation of this waste into valuable and marketable products would help to improve waste disposal. Indeed, the large annual production of this waste makes it a sustainable and renewable bio-source for the production of chemicals and fibers for advanced applications. In this work, new cellulose microfibrils (CMFs) with a tendril helical morphology and highly hydrated gel-like behavior were successfully extracted from CBS waste using a controlled chemical extraction process. During this study, several physico-chemical characterizations were carried out in order to identify the properties of each of the products at different stages of treatment. Microscopic observations show that the extracted CMFs have a tendril helical shape like climbing plant tendrils. Due to this special morphology, the extracted CMFs show a highly hydrated state forming a gel network without additional modifications. The as-extracted CMFs were used as adsorbent material for the removal of methylene blue from concentrated aqueous solution, as an application to wastewater treatment for the removal of basic dyes. Swelling properties, adsorption kinetics and isotherms were carried out in batch experiments. The results indicated that the CMFs have a high swelling capacity (190\%). The pseudo second order model can be effectively used to evaluate the adsorption kinetics and the adsorption isotherms can also be described well by the Langmuir isotherm model with a maximum adsorption capacity of $381.68 \mathrm{mg} \mathrm{g}^{-1}$. Thus, the as-extracted CMFs with unique characteristics have the potential to be used as efficient adsorbent material for the removal of different cationic dyes from industrial wastewater.

\section{Introduction}

Cellulose is considered the most abundant renewable organic polymer on earth having unique properties such as renewability, biodegradability, light weight and good mechanical properties. ${ }^{1}$ The word yearly biomass production of cellulose has been estimated to be over $7.5 \times 10^{10}$ tons, making it an inexhaustible source of raw material for environmentally friendly and biocompatible products. ${ }^{2}$ The major sources of cellulose are wood and cotton, but it can also be derived from a variety of sources, such as annual plants, marine animals,

\footnotetext{
${ }^{a}$ Materials Science and Nanoengineering Department, Mohamed 6 Polytechnic University, Lot 660 - Hay Moulay Rachid, Benguerir, 43150, Morocco. E-mail: mounir.elachaby@um6p.ma; Tel: +212662010620

${ }^{b}$ Montpellier SupAgro, UMR IATE, Montpellier F-34060, France

'Laboratoire des procédés chimiques et matériaux appliqués (LPCMA), Faculté polydisciplinaire de Béni-Mellal, Université Sultan Moulay Slimane, BP 592, 23000 Béni-Mellal, Morocco
}

marine biomass, fungi, bacteria, invertebrates and other agroindustrial wastes. ${ }^{3}$ Depending on the extraction process, various cellulose forms named fibers, microfibers, microfibrils, nanofibrils or nanocrystals can be extracted for numerous applications. ${ }^{4,5}$

In nature, depending on the degree of polymerization, the number of chains, and the way these chains pack together, the physiochemical properties of cellulose material can be enormously complicated and highly variable. ${ }^{6}$ Cellulose is considered to be water-insoluble compound and plays an important role in maintaining the structure of cell walls., ${ }^{2,7}$ However, the hierarchical arrangement of cellulose microfibrils (CMFs) in the cell wall varies depending on the origin and nature of plants. In the majority of plants, the MFCs are arranged as linear fibrils surrounded by others cell wall constituents. ${ }^{6}$ But in some cases, CMFs can adopt a defined tendril helical structure embedded in a soft matrix of polysaccharides, aromatic compounds and structural proteins, ${ }^{\mathbf{8}, 9}$ in which the sugar units and cellulose 
molecules take the form of asymmetric and chiral configurations, at the molecular level. In recent years, considerable efforts have been devoted to extract CMFs from cellulose-rich bio-sourced materials., ${ }^{3,7}$ However, the research in this filed is oriented toward of using new bio-sourced materials, new isolation processes, and new treatments for obtaining of CMFs with special characteristics to extend the application of cellulose.

Cocoa bean shells (CBS) are the seed coats covering the cocoa cotyledons and they constitute 12-20 wt\% of the dry cocoa beans, and they are separated from cocoa beans after roasting process. ${ }^{10}$ The word annual production of CBS is estimated at 700000 tons, ${ }^{10}$ in which the Mexico country produced annually around 27000 tons, it is the $13^{\text {th }}$ and the $6^{\text {th }}$ world's and Latinoamerica's largest cocoa producer, respectively. ${ }^{11} \mathrm{CBS}$ is thus an abundant and often underexploited by-product from the cocoa industry, which can represent serious disposal and environmental problems, if badly managed. ${ }^{\mathbf{1 2}}$ CBS is devoid of any marketable value and is mainly used as raw biomass material (as food additive, garden mulch and soil conditioner) or as fuel for boilers. ${ }^{\mathbf{1 0 , 1 3 , 1 4}}$ CBS is composed mainly of polysaccharides, hemicellulose, and lignin and other components. ${ }^{\mathbf{1 0 , 1 4}}$ making it a sustainable and renewable biosource for production of cellulose and others biomolecules for advanced applications. Indeed, the transformation of this waste into valuable and marketable products, such as cellulose derivatives, would help to valorize this waste and improve its disposal.

Owing its excellent properties, cellulose has generated much attention and interest during these last decades in both academic and industrial fields for various application. ${ }^{\mathbf{4 , 1 5}}$ Recently, the research focused on the use of cellulose and its modified forms as a new class of versatile adsorbents for wastewater treatment. ${ }^{16}$ Although many papers have been published so far discussing the importance of cellulose-based adsorbents in water pollution treatment. ${ }^{17-21}$ Indeed, cellulose-based adsorbents offer significant advantages over commercially available expensive materials/ adsorbents for water pollution treatment. ${ }^{22}$ Recently, cellulose derivatives have been extracted from bio-sourced materials and used as potential adsorbents for waste water treatment. Hussin et al. have reported the possible utilization of unmodified microcrystalline cellulose (MCC) extracted from oil palm fronds as adsorbent for removal of methylene blue (MB) from aqueous solution. ${ }^{23}$ They found that the extracted MCC exhibited a maximum adsorption capacity of $51.81 \mathrm{mg} \mathrm{g}^{-1}$. Batmaz et al. reported that cellulose nanocrystals extracted from cellulosic fibers can also be used as adsorbents for removal of cationic dyes (MB) from concentrated aqueous solutions, and a relatively high adsorption capacity was measured $\left(118 \mathrm{mg} \mathrm{g}^{-1}\right) \cdot{ }^{24}$ Douissa et al. have reported the efficiency of extracted cellulose from Posidonia oceanica to remove methylene blue from water. The appropriate adsorption capacity $\left(305.45 \mathrm{mg} \mathrm{g}^{-1}\right)$ was found higher than that obtained by raw material (Posidonia oceanica), showing the very good potentiality of extracted cellulose as no expensive adsorbent. ${ }^{25}$

Nevertheless, little research is focused on the extraction of cellulose derivatives from bio-sourced materials and their use directly without further modifications as potential adsorbents for wastewater treatment. In the current investigation, new CMFs with tendril helical morphology and highly hydrated gellike behavior were extracted from CBS waste, using the same chemical treatments that are largely used for cellulose extraction from typical terrestrial lignocellulosic materials, e.g. alkali and bleaching treatments. ${ }^{26,27}$ After its successful extraction, the as-obtained CMFs were successfully characterized in terms of their physico-chemical properties, and used as potential adsorbents for adsorption of cationic dyes from concentrated aqueous solution, as application for wastewater treatment for the removal of basic dyes. MB was chosen as adsorbate in this study, due to its strong adsorption on solid surfaces and its increased use in textile and paper industry. Swelling properties, adsorption kinetics and isotherms were carried out at batch experiments, and various theoretical models were used to evaluate the maximum adsorption capacity and to understand the adsorption mechanism.

\section{Materials and experimental details}

\section{Materials}

The dried CBS used in this study were obtained from fermented and roasted cocoa beans collected from Tabasco (Mexico) in 2016. Firstly, the CBS waste was chopped, then dried in a fluidized bed dryer (GRACO, TGA101) for $90 \mathrm{~min}$ at $60^{\circ} \mathrm{C}$. The dried CBS was milled using a Knife Shredder (RETSCH SM100, Haan, Germany) equipped with $5 \mathrm{~mm}$ sieve. Finally, it was stored in the dark at $4{ }^{\circ} \mathrm{C}$ until the extraction was performed. The moisture content of the CBS was about $4.59 \mathrm{wt} \%$. All the analytical grade chemicals used for purification and bleaching treatments were purchased from Sigma-Aldrich and used without further purification. The cationic Methylene Blue (MB) was purchased from Sigma Aldrich (M914025G) and used as received.

\section{Treatment of CBS and CMFs extraction}

CMFs in highly hydrated gel form were extracted from raw CBS using alkali and bleaching treatments. Firstly, a prewashing of ground CBS was carried out by distilled water for 1 hour at $60^{\circ} \mathrm{C}$ under mechanical stirring. Then, the prewashed CBS were treated 3 times with $4 \mathrm{wt} \% \mathrm{NaOH}$ solution at $80{ }^{\circ} \mathrm{C}$ for 2 hours under mechanical stirring. Then, the obtained alkali treatedCBS was subjected to a bleaching treatment with a solution made up of equal parts $(\mathrm{v} / \mathrm{v})$ of acetate buffer $(27 \mathrm{~g} \mathrm{NaOH}$ and $75 \mathrm{~mL}$ glacial acetic acid, diluted to $1 \mathrm{~L}$ of distilled water) and aqueous sodium chlorite (1.7 wt $\mathrm{NaClO}_{2}$ in water). The bleaching treatment was performed 3 times for $2 \mathrm{~h}$ at $80{ }^{\circ} \mathrm{C}$, under magnetic stirring. The obtained cellulose product was washed several times with distilled water, resulting in highly hydrated white gel composed of CMFs, as confirmed by microscopic observations. The overall steps these purification/ extraction and digital images of each obtained product are presented in Fig. 1.

\section{Characterization techniques}

Elementary analysis was performed mainly to determine the total carbon, oxygen, hydrogen and nitrogen contents before 


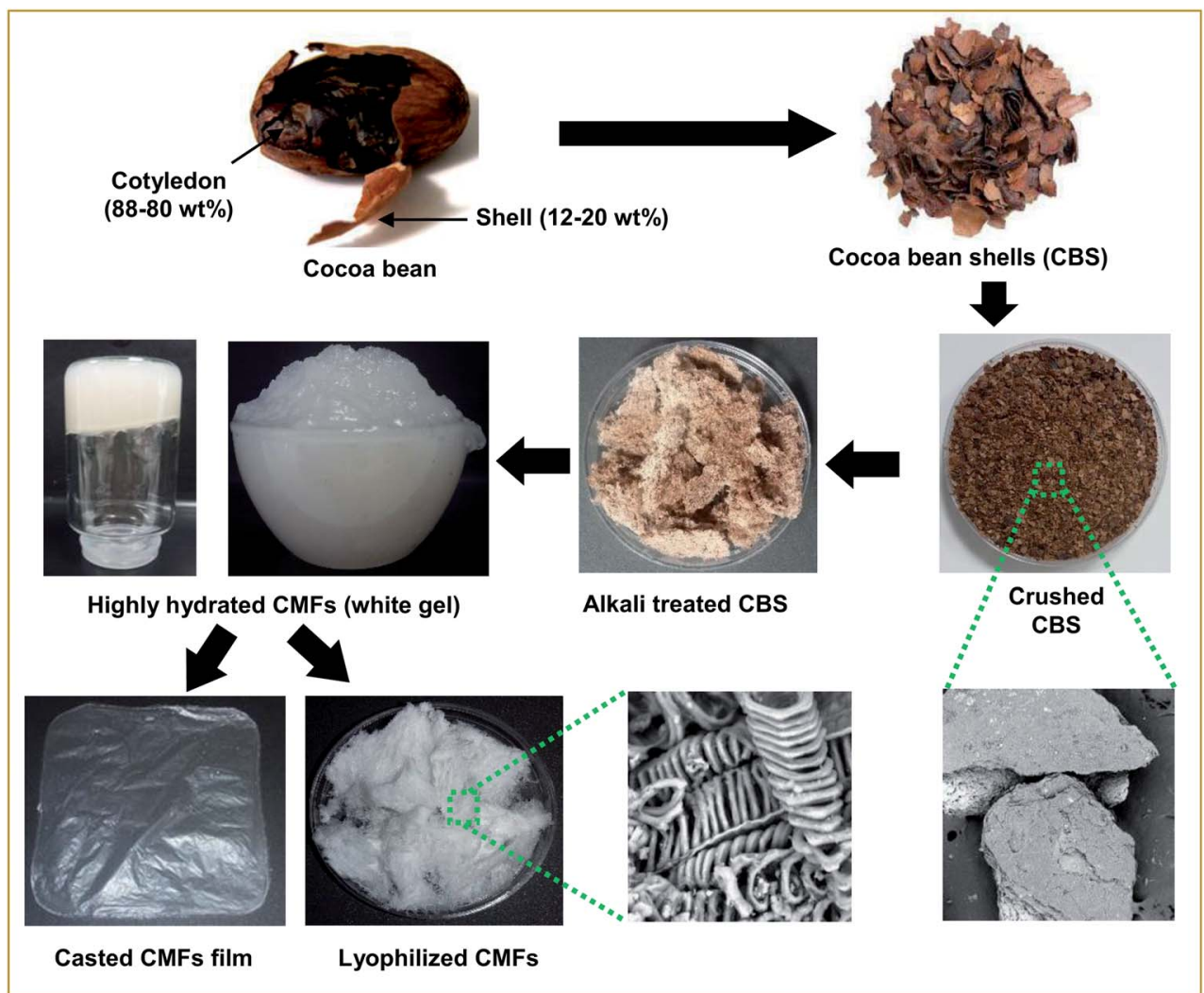

Fig. 1 Schematic representation of raw CBS treatment and digital images of the obtained products.

and after the extraction of cellulose microfibrils. It was carried out on elemental analyzer system $\mathrm{GmbH}$; analyzer vario MICRO V4.0.2. Morphology of samples was evaluated using a scanning electron microscope (SEM) (Phenom ProX) operated at $10 \mathrm{kV}$. Fourier Transform Infrared Spectroscopy (FTIR) of all studied samples were measured on a Tensor27 apparatus, the experiments were recorded in transmittance mode in the range of 4000-400 $\mathrm{cm}^{-1}$ with a resolution of $4 \mathrm{~cm}^{-1}$ and an accumulation of 16 scans. Thermogravimetric analysis (TGA) (Mettler Toledo) for all samples was conducted under a nitrogen atmosphere between 25 and $700{ }^{\circ} \mathrm{C}$, at a heating rate of $10^{\circ} \mathrm{C} \mathrm{min}^{-1}$. $\mathrm{X}$-ray diffraction (XRD) characterizations of samples were performed on a Bruker diffractometer D8 Advance using $\mathrm{Cu}-\mathrm{K} \alpha$ radiation. The diffraction patterns were obtained at diffraction angles between 5 and $50^{\circ}$, at room temperature. The crystallinity index $(\mathrm{CrI} \%)$ of the samples was estimated using Segal's equation: $\mathrm{CrI}=\left(\left(I_{002}-I_{\mathrm{am}}\right) / I_{002}\right) \times 100,{ }^{28}$ where $I_{002}$ and $I_{\mathrm{am}}$ are the peak intensities of crystalline and amorphous cellulose, respectively.

\section{Swelling ratio}

The equilibrium swelling ratio (SR) of CMFs was measured in distilled water at room temperature. For that, structural stable film with thickness of $180 \mu \mathrm{m}$ was successfully casted from the obtained CMFs gel on Petri dish and air dried (Fig. 1). To determine the SR of the film sample, square dried film with an initial weight $\left(W_{0}\right)$ was placed in a glass crystallizer with excess water. The swollen film was removed after an interval of time. The excess water on the surface of film was removed with filter paper, and the weight of each sample $\left(W_{\mathrm{t}}\right)$ was measured. The percentage of SR (\%) was calculated using the following eqn (1):

$$
\operatorname{SR}(\%)=\frac{\left(W_{\mathrm{t}}-W_{0}\right)}{W_{0}} \times 100
$$

\section{Adsorption studies}

All adsorption studies were performed at batch experiments. A stock solution of MB at a concentration of $1000 \mathrm{mg} \mathrm{L}^{-1}$ was prepared in distilled water and suitably diluted to the required initial concentrations. The concentration of the MB dye for all samples during the experimental tests were measured using a UV-visible spectrophotometer (PerkinElmer Lambda 25 spectrophotometer) at a wavelength of $664 \mathrm{~nm}$ which correspond to the maximum absorbance for MB. ${ }^{24}$ For each experiment, the concentration of MB aqueous solution was obtained from linear standard calibration curves $\left(R^{2}=0.999\right)$.

\section{Adsorption kinetics}

The adsorption experiments were conducted at room temperature using an initial concentration of $\mathrm{MB}$ of $50 \mathrm{mg} \mathrm{L}^{-1}$. For all experiments, the $\mathrm{pH}$ of the initial $\mathrm{MB}$ solution was kept at 7 . After that, a pre-weighted amount of adsorbent $(10 \mathrm{mg})$ was added to $20 \mathrm{~mL}$ of MB solution in glass bottles, and the mixture was slowly stirred $(100 \mathrm{rpm})$ for various contact time intervals (5-150 min). At a predetermined time interval, sample aliquots 
$(\sim 3 \mathrm{~mL})$ were withdrawn from the bottle, using $25 \mathrm{~mm}$ disposable syringe filter $(0.45 \mu \mathrm{m}$ cellulose acetate membrane), and were either introduced directly into plastic cell or diluted with a suitable volume of distilled water to allow for Beer's law concentration analysis on the UV-vis spectrophotometer. The adsorbed amount of $\mathrm{MB} q_{t}\left(\mathrm{mg} \mathrm{g}^{-1}\right)$, at a particular time interval $t$, was calculated using the following expression (2):

$$
q_{t}=\frac{\left(C_{0}-C_{t}\right) V}{W}
$$

where $C_{0}\left(\mathrm{mg} \mathrm{L}^{-1}\right)$ is the initial concentration of $\mathrm{MB}, C_{t}\left(\mathrm{mg} \mathrm{L}^{-1}\right)$ is the dye concentration at time $t, V(\mathrm{~L})$ is the volume of the solution and $W(\mathrm{~g})$ is the weight of used adsorbent.

\section{Adsorption at equilibrium state}

The adsorption isotherm at the equilibrium state was carried out in the same conditions by varying the initial MB concentration from 25 to $500 \mathrm{mg} \mathrm{\textrm {L } ^ { - 1 }}$. The adsorption capacity $q_{\mathrm{e}}\left(\mathrm{mg}^{-1}\right)$ at the equilibrium was measured using the following eqn (3):

$$
q_{\mathrm{e}}=\frac{\left(C_{0}-C_{\mathrm{e}}\right) V}{W}
$$

where $C_{0}\left(\mathrm{mg} \mathrm{L}^{-1}\right)$ is the initial concentration of $\mathrm{MB}, C_{\mathrm{e}}\left(\mathrm{mg} \mathrm{L}^{-1}\right)$ is the concentration of $\mathrm{MB}$ at equilibrium (150 min of contact time), $V(\mathrm{~mL})$ is the volume of the solution and $W(\mathrm{mg})$ is the weight of adsorbent.

\section{Results and discussion}

\section{Extraction of CMFs}

CMFs were extracted from CBS by means of controlled chemical treatments. Obviously, the initial ground CBS grains have brown color (Fig. 1), due to its diversified constituents (lignin, hemicellulose, cellulose, protein, pectin and others). Starting with the alkali treatment of CBS, the main objective of this treatment was to eliminate the whole non-cellulosic cementing components (lignin, hemicelluloses, pectin, ash, and other impurities), resulting in the alkali-treated CBS. During this alkali treatment, some alkali-labile linkages (ether and ester linkages) between lignin monomers or between lignin and polysaccharides may have been broken, resulting in a partial breakdown of CBS grains into interconnected fibers, with yellowish brown color (Fig. 1). The yield of this alkali-treated CBS was about 39\% (in dry mass). The following treatment was the bleaching treatment, with the main purpose to obtain pure cellulosic fibers. This whiteness and purification is to be achieved simply by removing the residual lignin and the other unwanted non-cellulosic components adhering to the cellulose fibers, with the help of bleaching agents. During this treatment, the residual lignin molecules react with $\mathrm{NaClO}_{2}$ and an oxidative fragmentation takes place resulting into soluble lignin molecules in the bleaching solution, which lead into total removal of lignin, and leave the CMFs unaltered. ${ }^{29}$ The yield of the extracted CMFs was determined at $20 \%$ (in regard to the initial weight of raw CBS). Very interestingly, the CMFs were extracted in highly hydrated white gel form without any further chemical treatment (Fig. 1).

It is noteworthy that the extracted CMFs gel can easily be transformed into powdered form via freeze drying process (Fig. 1) or in form of stable film using the casting process followed by air drying (Fig. 1). This was surprising, because only the bacterial cellulose or modified cellulose can exhibit this characteristic. $^{\mathbf{3 0} 31}$ It have been reported that the natural extracted cellulose could form a thick gel or highly hygroscopic material after a suitable additional modification such as treatments in an alkaline aqueous solution with cooling by physical cross-linking. ${ }^{32}$ Herein, we report that a highly hydrated CMFs gel can be directly extracted from raw CBS via simple bleaching treatment. Morphological analysis by SEM showed that the extracted cellulose exhibits a mixture of linear long microfibrils and tendril helical microfibrils (see below). May be this special morphology is responsible for obtaining of gel-like cellulose with highly hydrate state.

\section{Morphology of CBS and CMFs}

As a widely employed technique, SEM was used to investigate and identify the morphological features of CBS and extracted CMFs, examples of the obtained SEM results are shown in Fig. 2. According to the above discussion, lignin molecules, hemicelluloses and other extractive substances were removed from CBS by means of bleaching treatment, leaving only the cellulose product. From the SEM results, it is clearly found that

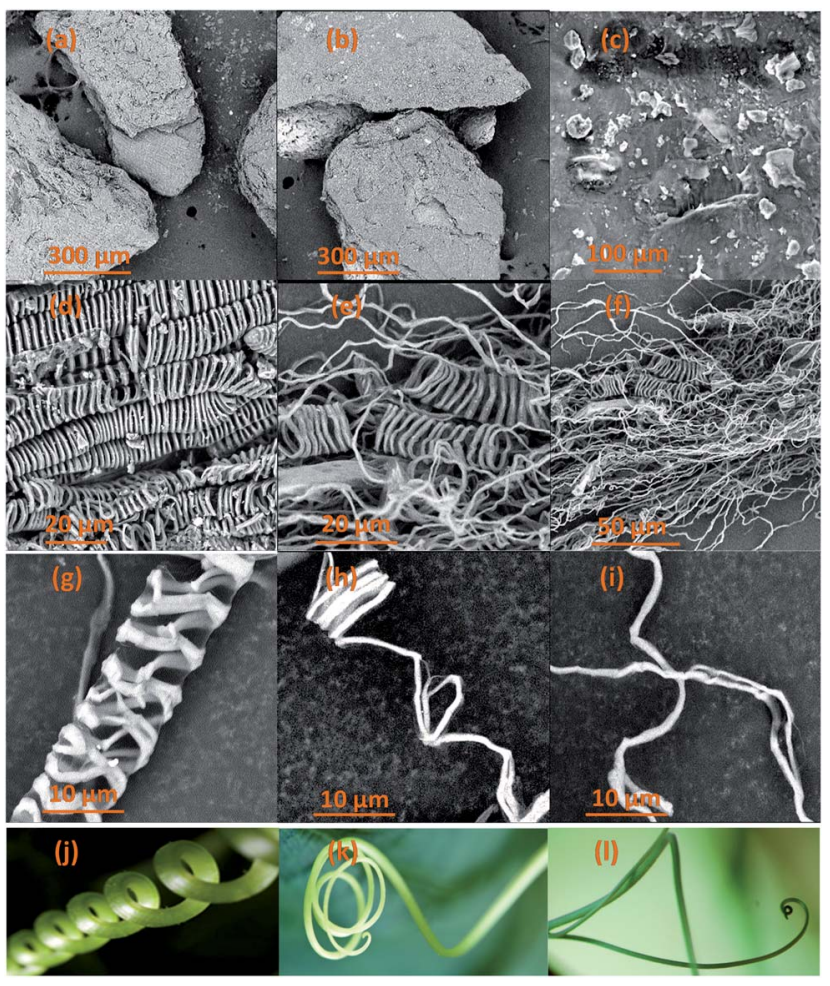

Fig. 2 SEM images of raw CBS $(a-c)$, extracted CMFs $(d-i)$ samples and examples of plant tendrils $(j-l)$ comparable to the morphology of the extracted CMFs. 
Table 1 Elementary analysis of CBS, alkali treated CBS and extracted MCFs

\begin{tabular}{lllll}
\hline & $\mathrm{C}(\%)$ & $\mathrm{H}(\%)$ & $\mathrm{O}(\%)$ & $\mathrm{N}(\%)$ \\
\hline CBS & $41.64 \pm 0.33$ & $5.80 \pm 0.02$ & 50.27 & $2.29 \pm 0.03$ \\
Alkali treated CBS & $35.86 \pm 0.12$ & $5.34 \pm 0.01$ & 58.39 & $0.41 \pm 0.01$ \\
Extracted CMFs & $39.00 \pm 0.10$ & $6.06 \pm 0.18$ & 54.92 & $0.00 \pm 0.00$
\end{tabular}

the morphologies of CBS and the extracted CMFs are extremely different. The crushed CBS exhibit a layer of surface deposits mostly composed of lignin, hemicellulose, and other noncellulosic substances that cover the CMFs inside (Fig. 2a-c). For the extracted CMFs, a remarkable finding of this new extraction can be seen in Fig. $2 \mathrm{~d}-\mathrm{i}$. It is found that the morphology of CMFs consisted of a mixture of linear long microfibrils and tendril helical microfibrils. The helical shape of the obtained CMFs was comparable to that of a climbing plant tendril (Fig. 2j-l). The average diameter of individual microfibril helices was determined at $10 \mu \mathrm{m}$, whereas the average diameter of microfibril forming helices was measured at about $1 \mu \mathrm{m}$. Nonetheless it was not possible to determine the average length of CMFs by SEM microscopy analysis, because the CMFs are much entangled forming a spaghetti-like structure (Fig. 2f).

\section{Elementary analysis}

Table 1 shows the result obtained from elemental analysis for all studied samples (CBS, alkali treated CBS and extracted CMFs). From this result, it should be noted that all samples present high carbon and oxygen contents, indicating the organic nature of these samples. The determination of nitrogen $(\mathrm{N})$ in CBS sample indicates that the presence of proteins in the original sample. Notably, a total removal of $\mathrm{N}(\%)$ content in extracted CMFs indicates a total elimination of proteins after bleaching treatment. It must also be noticed that the ratio $\mathrm{O} / \mathrm{C}$ of the extracted CMFs was calculated at about 1.40 , wherein 0.83 is the theoretical value of pure cellulose. ${ }^{33}$ The relatively high $\mathrm{O} /$ C ratio in our case is probably due to the excess of hydroxyl groups in the surface of microfibrils, which can explain in first time the formation of highly hydrated CMFs gel directly after the extraction process.

\section{Structure and crystallinity}

Direct information about changes in chemical functionality can be obtained by FTIR spectroscopy which has been extensively used for structural analysis of the material before and after chemical treatments. FTIR spectra of raw CBS, alkali treated CBS and extracted CMFs are shown in the Fig. 3. Additionally, the FTIR spectrum of commercial MCC is also shown in this Fig. 3 for eventual comparison. Obviously, all samples spectra exhibit the characteristic bands of cellulose molecule. The absorption bands located at $3300 \mathrm{~cm}^{-1}$ and $2980 \mathrm{~cm}^{-1}$ are attributed to the $-\mathrm{OH}$ stretching vibration of hydrogen bonded hydroxyl groups, showing the hydrophilic tendency of all samples ${ }^{34}$ and the $-\mathrm{CH}$ groups of cellulose molecule, ${ }^{29}$ respectively. In addition, the absorption band at $1610 \mathrm{~cm}^{-1}$ is attributed to the adsorbed water. ${ }^{35}$ Beside these absorption bands, other specific absorption bands can also be seen in all spectra. The band centered at $1160 \mathrm{~cm}^{-1}$ is assigned to the $\mathrm{C}-\mathrm{O}-\mathrm{C}$ stretching of the $\beta-1,4$-glycosidic ring linkages between the D-glucose units in cellulose. ${ }^{29}$ Noticeably, this band was gradually going intense from raw CBS to extracted CMFs, indicating that the cellulose content was increased during different chemical treatments starting from raw CBS and ending up with extracted CMFs. In addition, the two bands observed at 1035 and $894 \mathrm{~cm}^{-1}$ in all spectra are attributed to the $\mathrm{C}-\mathrm{O}$ stretching and $\mathrm{C}-\mathrm{H}$ rocking vibrations of cellulose of the carbohydrates. ${ }^{36}$

The most distinct spectral changes that can be detected in the alkali treated CBS and the extracted CMFs comparing to the raw CBS are the absorption band located at $1742 \mathrm{~cm}^{-1}$, which is

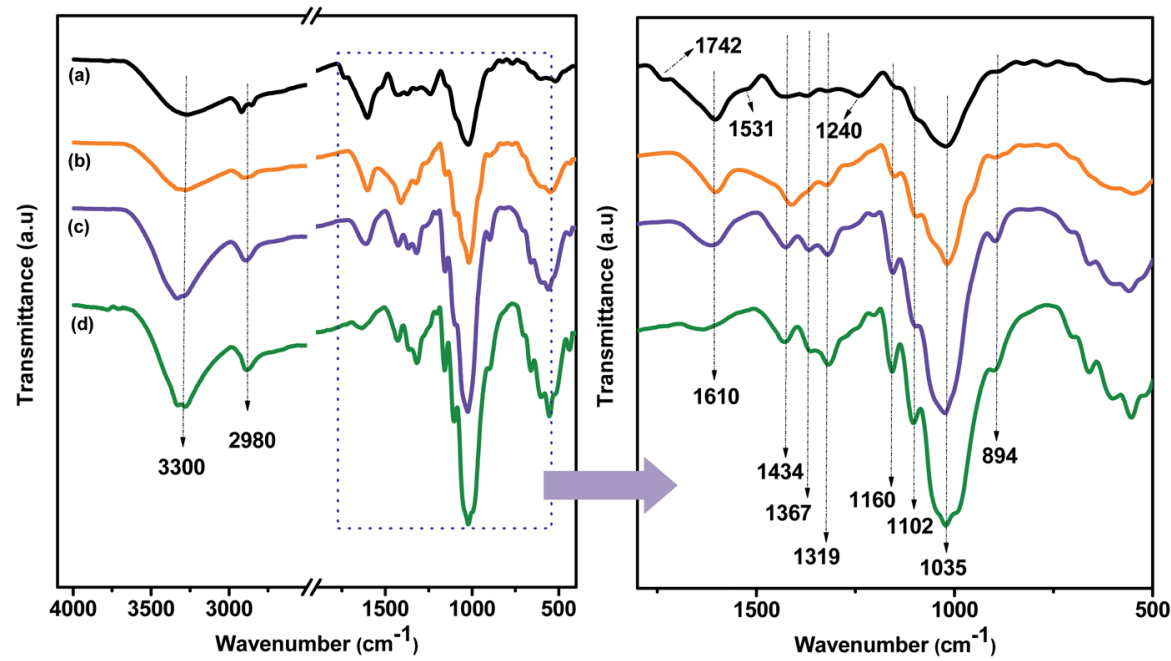

Fig. 3 FTIR spectra of CBS (a), alkali treated CBS (b) and extracted CMFs (c). The FTIR spectrum of commercial MCC (d) is included for comparison. 
assigned to the uronic ester and acetyl groups of hemicelluloses and the ester linkage of carboxylic group of the ferulic and $p$-coumaric acids of lignin, ${ }^{37}$ and the absorption band located at $1531 \mathrm{~cm}^{-1}$ which is due to the stretching vibration of $\mathrm{N}-\mathrm{H}$ band of the protein amide II structure, ${ }^{38}$ and the $\mathrm{C}=\mathrm{C}$ stretching from aromatic hydrocarbons of lignin. ${ }^{39}$ Additionally, the band observed at $1240 \mathrm{~cm}^{-1}$ is attributed to the $\mathrm{C}-\mathrm{O}$ out of plane stretching vibration of the aryl group in the lignin molecules. ${ }^{36}$ These three bands are clearly present in raw CBS, as it can be seen from the Fig. 3b. However, after the alkali treatment, in the alkali treated SBC spectrum, these bands were drastically reduced confirming that the lignin and hemicelluloses were not completely removed.

The disappearance of these bands in the spectrum of the extracted CMFs was observed, which is an indication that all non-cellulosic components were completely removed after the bleaching treatment. These results were already confirmed by the elemental analysis data (Table 1 ) in which the \% $\mathrm{N}$ content was totally removed after bleaching treatment.

The FTIR spectra of all samples show another absorption band located at $1102 \mathrm{~cm}^{-1}$ and it is attributed to presence of $\beta$-glucosidic ether linkages $(\mathrm{C}-\mathrm{O}-\mathrm{C})$ resulted in the vibration of wagging, deformation and twisting modes of anhydroglucopyranose ring skeleton. ${ }^{40}$ In addition, the absorbance bands at $1434 \mathrm{~cm}^{-1}, 1367 \mathrm{~cm}^{-1}$ and $1319 \mathrm{~cm}^{-1}$ in alkali treated CBS and extracted CMFs samples were mainly associated to the presence of cellulose chain. ${ }^{28}$ It is interesting to observe that raw CBS sample did not exhibit bands at $1319 \mathrm{~cm}^{-1}$ and $1367 \mathrm{~cm}^{-1}$, as shown in Fig. 3b. This is an indication that the CMFs were embedded in the matrix of amorphous non-cellulosic components in the raw CBS, as observed by SEM analysis (Fig. 2). Besides that, the extracted CMFs from raw CBS was comparable with the commercial available MCC in terms of FTIR analysis (Fig. 3), suggesting that pure cellulose has been successfully produced from raw CBS.

XRD analysis was performed to investigate the crystalline structure and the crystallinity index (CrI) of all studied

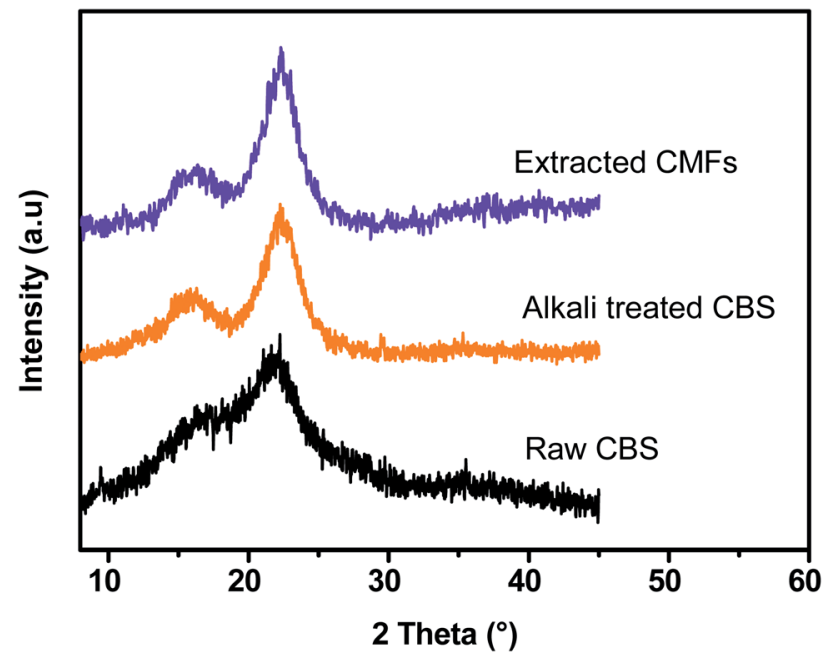

Fig. 4 XRD patterns of CBS, alkali treated CBS and extracted CMFs. samples (raw CBS, alkali treated CBS and extracted CMFs). Herein, it should be noted that the presence of a crystallinity feature in all samples is generated from the ordered structure of cellulose, which is generated from intra- and intermolecular hydrogen bonding occur in cellulose via hydroxyl groups, resulting in various ordered crystalline arrangements. ${ }^{29}$ Fig. 4 shows the XRD patterns for raw CBS, alkali treated CBS and extracted CMFs. From this result, all samples show three major peaks located at $2 \theta=14.9^{\circ}, 16.8^{\circ}$, and $22.6^{\circ}$, which are characteristic of the crystal polymorphs of cellulose. These peaks correspond to the $1 \overline{1} 0,110$ and 200 crystalline planes, respectively. ${ }^{27}$

The crystallinity index (CrI) determined was found to be about $40.46 \%, 71.3 \%$, and $75.57 \%$ for raw CBS, alkali treated CBS and extracted CMFs, respectively, demonstrating that the crystallinity of the material progressively increases during the chemical extraction. In the case of raw CBS, the cellulose is embedded in the matrix of amorphous non-cellulosic components thus a low crystallinity is determined. ${ }^{29}$ In the case of CMFs, the increased crystallinity was ascribed to the total removal of amorphous components, leading only cellulose structure that contains amorphous and ordered regions, which was also confirmed by FTIR analysis of all studied samples at different stages of treatment (Fig. 3).
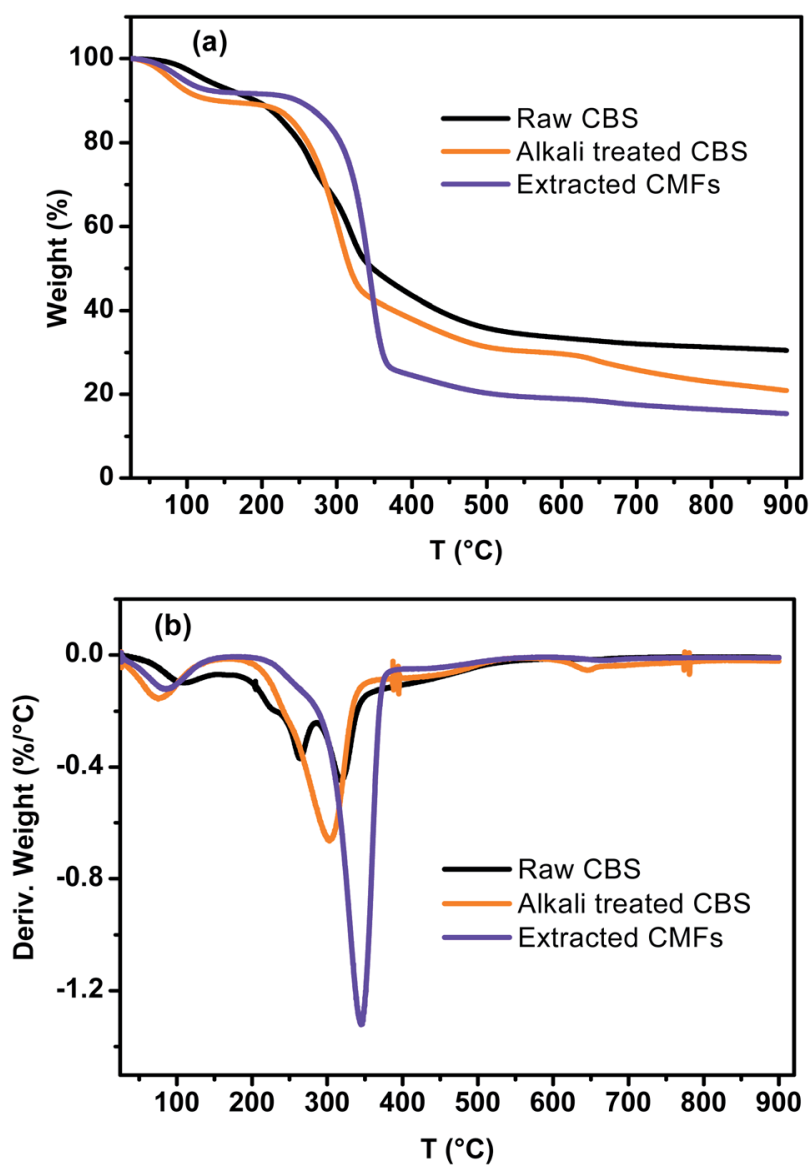

Fig. 5 TGA (a) DTG (b) curves of CBS, alkali treated CBS and extracted CMFs. 


\section{Thermal stability}

Fig. 5 shows the TGA-DTG curves of CBS, alkali treated CBS and extracted CMFs. From these results, it can be viewed that all samples demonstrated a weight loss at around $100{ }^{\circ} \mathrm{C}$, which was caused by evaporation of loosely bound moisture on the surface and the intermolecular hydrogen bonded chemisorbed water. $^{21}$ The degradation of raw CBS occurs at three different stages. The first and second stages start forward at around $184{ }^{\circ} \mathrm{C}$ and $235{ }^{\circ} \mathrm{C}$ respectively, which are likely due to the decomposition of non-cellulosic components, such as hemicelluloses and lignin. ${ }^{\mathbf{4 1}}$ The corresponding maximum temperatures from DTG curves were observed at $224^{\circ} \mathrm{C}$ and $262^{\circ} \mathrm{C}$. The third degradation stage of raw CBS starts at $286^{\circ} \mathrm{C}$ with corresponding maximum temperature of $323{ }^{\circ} \mathrm{C}$, which is due to degradation of cellulose molecules. ${ }^{42}$ For alkali treated CBS, a single decomposition stage is observed, which occurs between 184 and $360^{\circ} \mathrm{C}$, indicated by a shoulder peak at DTG curve with a maximum temperature of $304{ }^{\circ} \mathrm{C}$. This degradation is due to decomposition of small amounts of lignin and hemicelluloses that are still presented in this sample as well as of cellulose molecules. This finding likely reflect the partial elimination of lignin, hemicelluloses and other non-cellulosic segments, ${ }^{43}$ which are started to decompose at low temperatures $\left(<230{ }^{\circ} \mathrm{C}\right)$, this is confirmed by the absence of small shoulder DTG peaks observed in raw CBS curve.

Concerning the extracted CMFs, the degradation starts at $269{ }^{\circ} \mathrm{C}$ and the corresponding maximum temperature is reached at $345{ }^{\circ} \mathrm{C}$. It can be noted that the onset thermal decomposition shifted to higher temperature, in regard to raw CBS and alkali treated CBS. This is due to the purification process which lead to the complete elimination of hemicelluloses and lignin residues and other impurities. ${ }^{27,28}$ This finding is comparable to that observed for cellulose microfibers extracted from sugarcane bagasse, ${ }^{26,27}$ and red algal waste. ${ }^{28}$

Generally, cellulose thermal degradation involves dehydration, depolymerization and decomposition of glycosyl-units and then formation of a charred residue. ${ }^{34}$

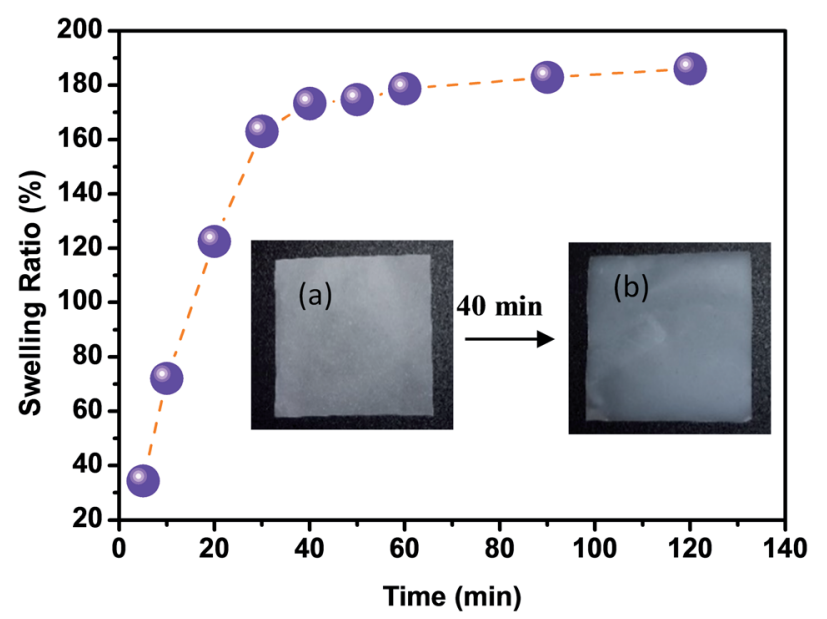

Fig. 6 Swelling ratio of extracted CMFs in form of casted film (inset: CMFs film before (a) and after (b) its swelling at $40 \mathrm{~min}$ ).
Additionally, the TGA analysis showed minimum residual mass for extracted CMFs in regard to raw CBS and alkali treated CBS samples, which probably due to the absence of the charred residue that can be generated from the degradation of lignin and hemicelluloses. ${ }^{37}$

\section{Swelling ratio of CMFs}

With regard to the use of CMFs as adsorbent for removal of MB from concentrated aqueous solution, the swelling capacity of the as-extracted CMFs was investigated. It is noteworthy that the CMFs were extracted in highly hydrated gel form (Fig. 1), and they were easily transformed into powdered form via freeze drying process or in form of stable film using the casting process followed by air drying. Indeed, the swelling ratio (SR) of CMFs based film was measured by immersing of such film in distilled water for various contact time intervals. The obtained results are shown in Fig. 6. From these results, the SR increased rapidly with the prolongation of immersing time and reached swelling equilibrium within $40 \mathrm{~min}$. The high obtained SR was about $190 \%$ and reached after $120 \mathrm{~min}$, suggesting that the CMFs have a high capacity to absorb water. This behavior is due to the special morphology of the extracted microfibrils (mixture of linear long microfibrils and tendril helical microfibrils) as well as the entanglement network (spaghetti-like structure) formed by the microfibrils at their solid state, as observed by SEM observations (Fig. 2). This network may have a high capacity to absorb water throughout its void regions. Additionally, the extracted CMFs may have an excess of hydroxyl groups on their surface, as deduced from the high $\mathrm{O} / \mathrm{C}$ ratio obtained by elemental analysis (Table 1 ). The hydroxyl groups on the surface of microfibrils are able to interact with water molecules, thus improving the swelling capacity.

\section{Application of the extracted CMFs for MB adsorption}

Freeze dried CMFs were tested as bioadsorbent for removal of MB from concentrated aqueous solution. Adsorption kinetic

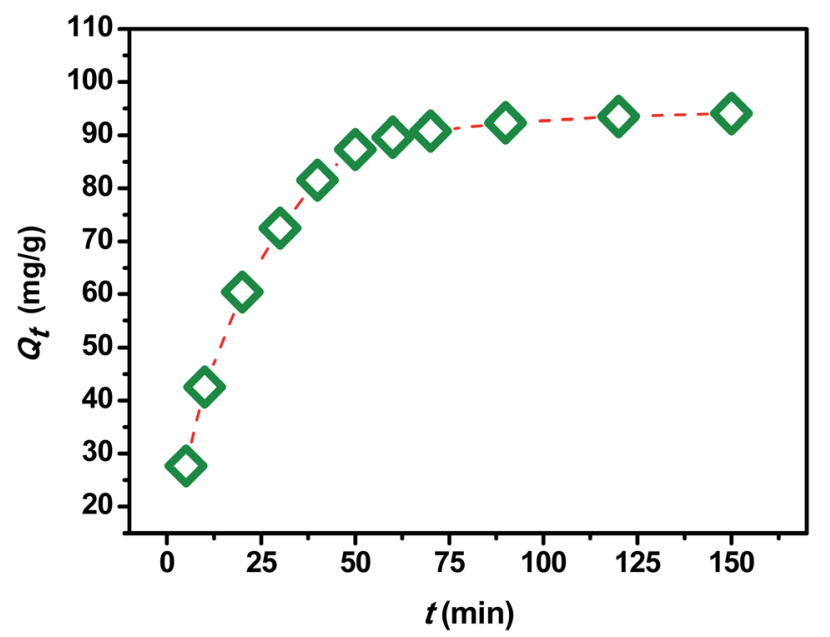

Fig. 7 Adsorption capacity of the extracted CMFs as function of the contact time $(t)$. 
and isotherm were evaluated at controlled conditions and the obtained results were analyzed and simulated using kinetic and isotherm models. The as-extracted CMFs exhibit native cellulose-like structure and well-defined morphology. It was observed that CMFs is microscale material consisting of linear long microfibrils and tendril helical microfibrils, forming an entangled network (spaghetti-like structure). As such, CMFs in aqueous solution contain micropores in the case of helical microfibrils and contain naturally active hydroxyl groups on their surfaces. In conventional theory of adsorption, there are two adsorption processes, firstly, adsorbate must first be in contact with adsorbent (mass transfer of adsorbate) then the filling of pores due to capillary forces (diffusion of adsorbate through pores). ${ }^{16}$ In our case, the removal of MB by CMFs can be ensure by both adsorption processes.

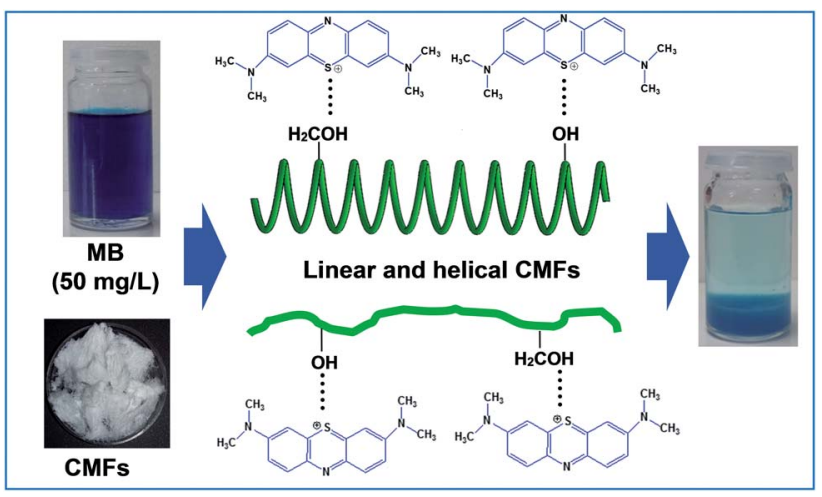

Fig. 8 Adsorption mechanism of MB molecule onto CMFs.

\section{Effect of contact time and adsorption kinetics}

In order to investigate the influence of the contact time on the removal of MB by the extracted CMFs, the adsorption capacity was studied at various times ranging from 0 to $150 \mathrm{~min}$. The obtained results are shown in Fig. 7. From this, it can be observed that the MB adsorption process on CMFs presents generally two phases; an initial rapid phase, where adsorption capacity sharply increased and reached an equilibrium state within $60 \mathrm{~min}$, due to the rapid surface adsorption, and a second slow phase associated with the internal surface created by helical morphology of CMFs. This can be explained by the fact that initially the adsorption sites of extracted CMFs were vacant and therefore easily accessible to the MB dye molecules, considering the associative interactions that take place between the MB cationic dye and the CMFs' surface, ${ }^{44}$ as shown in the representative scheme in Fig. 8. However after this initial stage, the remaining active sites of extracted CMFs are difficult to be occupied due to repulsive force towards free MB molecules over times which also resulted in the lower adsorption rate. When repulsive and driving force reached the equilibrium, the reaction equilibrium achieved and the MB adsorption would not be influenced by time of the reaction any more.

In order to evaluate the kinetic mechanism that controls the MB biosorption process, the obtained adsorption data were analyzed and simulated using four kinetic models including the pseudo first order, pseudo second order, Elovich and intraparticle diffusion models. It should be noted that the conformity between the experimental data and the predicted model is based on the values of the determination coefficients $\left(R^{2}\right)$; thus, the value of $R^{2}$ closest to the unit will indicate the appropriate model to describe the adsorption kinetic of MB.
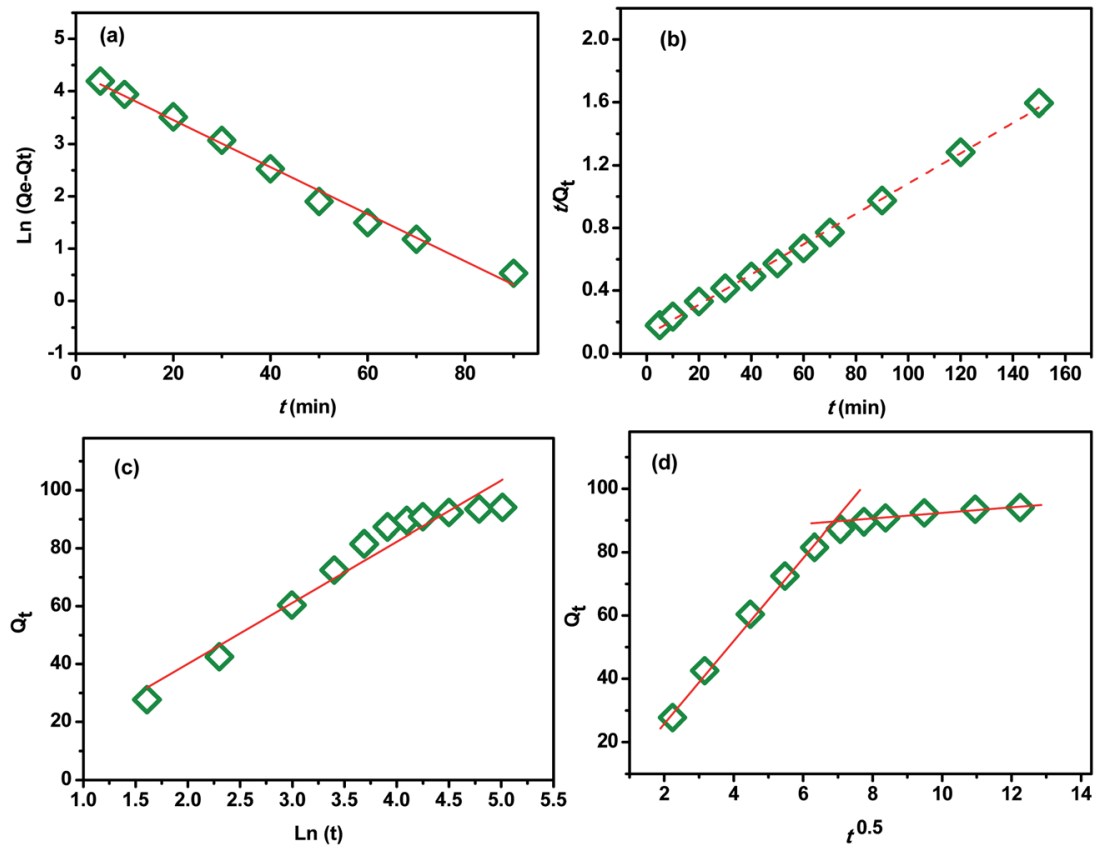

Fig. 9 (a) Pseudo-first order equation, (b) pseudo-second order equation, (d) Elovich and (c) intraparticle diffusion. 
Pseudo first order and pseudo second order models. The pseudo first order (eqn (4)) and the pseudo second order (eqn (5)) models were most commonly used to determine the rate constants and to analyze the adsorption process. The linear forms of these kinetic models can be expressed as:

$$
\begin{gathered}
\ln \left(q_{\mathrm{e}}-q_{t}\right)=\ln q_{\mathrm{e}}-k_{1} t \\
t / q_{t}=1 / k_{2} q_{\mathrm{e}}^{2}+\left(1 / q_{\mathrm{e}}\right) t
\end{gathered}
$$

where $q_{\mathrm{e}}\left(\mathrm{mg} \mathrm{g}^{-1}\right)$ is the adsorption capacity at equilibrium state, $q_{t}\left(\mathrm{mg} \mathrm{g}^{-1}\right)$ is the adsorption capacity at contact time $t$ (min), $k_{1}\left(\mathrm{~min}^{-1}\right)$ and $k_{2}\left(\mathrm{~g} \mathrm{mg}^{-1} \mathrm{~min}^{-1}\right)$ are the equilibrium rate constants of pseudo-first-order and pseudo second order models, respectively. For the pseudo first order model, $q_{\mathrm{e}}$ and $k_{1}$ were determined from the slope and intercept of the plot of eqn (4). While for the pseudo second order, $q_{\mathrm{e}}$ and $k_{2}$ can be calculated from the slope and intercept of the plot of eqn (5). The experimental data were fitted linearly by using eqn (4) and (5), and the obtained results are shown in Fig. 9a and b, respectively. According to the obtained kinetic parameters summarized in Table 2, the $R^{2}$ value of the pseudo-second-order $\left(R^{2}=0.997\right)$ is higher compared with that obtained from the pseudo-first-order $\left(R^{2}=0.988\right)$. Moreover, the experimentally determined ( $q_{\text {e,exp }}$ ) value, obtained from the linear plot, for the pseudo-first-order model did not agree with the calculated value $(q$ e,calcul $)$ as mentioned in Table 2 . Indicating that the adsorption process of MB onto extracted CMFs did not comply with the latter model. However, the linear plot of $t / q_{t}$ versus $t$ showed a good agreement between experimental and calculated values of $q_{\mathrm{e}}$. These findings indicate that the pseudo-second-order mechanism is the predominant in the MB adsorption process for the used cellulose.

Therefore, this evidence indicated that the adsorption of $\mathrm{MB}$ onto CMFs follows pseudo-second-order kinetic model. A

Table 2 Parameters of different kinetic models for MB adsorption on the extracted CMFs

\begin{tabular}{lll}
\hline Kinetic model & Parameter & Values \\
\hline Pseudo-first order model & $k_{1}\left(\mathrm{~min}^{-1}\right)$ & 0.1036 \\
& $q_{\mathrm{e}, \text { calcul }}\left(\mathrm{mg} \mathrm{g}^{-1}\right)$ & 78.10 \\
Pseudo-second order model & $R^{2}\left(k_{2}\left(\mathrm{~g} \mathrm{mg}^{-1} \mathrm{~min}^{-1}\right)\right.$ & 0.988 \\
& $q_{\mathrm{e}, \text { calcul }}\left(\mathrm{mg} \mathrm{g}^{-1}\right)$ & 0.0007 \\
& $R^{2}$ & 104.16 \\
Elovich model & $q_{\mathrm{e}(\exp )}\left(\mathrm{mg} \mathrm{g}^{-1}\right)$ & 0.997 \\
& $\alpha\left(\mathrm{g} \mathrm{g}^{-1} \mathrm{~min}^{-1}\right)$ & 95.05 \\
Intraparticle diffusion model & $\beta\left(\mathrm{g} \mathrm{mg}^{-1}\right)$ & 0.127 \\
& $R^{2}$ & 0.047 \\
& First stage & 0.939 \\
& $k_{\mathrm{i} 1}\left(\mathrm{mg} \mathrm{g}^{-1} \min ^{-0.5}\right)$ & 12.40 \\
& $C_{\mathrm{i} 1}\left(\mathrm{mg} \mathrm{g}^{-1}\right)$ & 2.55 \\
& $R^{2}$ & 0.987 \\
& $\left.\mathrm{Second} \mathrm{stage}^{-0.5}\right)$ & \\
& $k_{\mathrm{i} 2}\left(\mathrm{mg} \mathrm{g}^{-1} \min ^{-0.5}\right)$ & 0.97 \\
& $C_{\mathrm{i} 2}\left(\mathrm{mg} \mathrm{g}^{-1}\right)$ & 82.52 \\
& $R^{2}$ & 0.918
\end{tabular}

similar trend was also reported for the adsorption of $\mathrm{MB}$ on cellulose extracted from Posidonia oceanica, ${ }^{25}$ and on cellulose nanocrystal filled polyacrylamide nanocomposite hydrogels, ${ }^{45}$ which the adsorption rate was determined by the free adsorption site on the surface of the adsorbent.

Elovich model. The Elovich model (eqn (6)) was used to describe the chemical adsorption mechanism of $\mathrm{MB}$ onto extracted CMFs, because it is based on a general second-order reaction mechanism for heterogeneous adsorption processes. ${ }^{45}$ The Elovich equation is expressed in linear form as:

$$
q_{t}=\frac{1}{\beta} \ln (\alpha \beta)+\frac{1}{\beta} \ln t
$$

where $\alpha\left(\mathrm{mg} \mathrm{g}^{-1} \mathrm{~min}^{-2}\right)$ is the initial adsorption rate and $\beta$ ( $\mathrm{g}$ $\mathrm{mg}^{-1} \mathrm{~min}^{-1}$ ) is the desorption constant, which is related to the activation energy and the extent of surface coverage for chemisorption. ${ }^{45}$ The experimental data in Fig. 9d were fitted linearly by using eqn (6) $\left(q_{t} v s\right.$. $\left.\ln t\right)$. The values of $\alpha, \beta$, and $R^{2}$ are calculated and listed in Table 2 . From the obtained data, it can be seen that the Elovich model don't fit to the experimental data based on its $R^{2}$ value (0.93). This further indicates that the adsorption of MB onto the extracted CMFs is not a chemical process. $^{45}$

Intra-particle diffusion model. The intra-particle diffusion model (eqn (7)) was used to further determine the mechanism of MB removal in terms of dye molecules diffusion. The intraparticle diffusion equation is expressed as:

$$
q_{t}=k_{\mathrm{i}} t^{1 / 2}+C_{\mathrm{i}}
$$

where $q_{t}\left(\mathrm{mg} \mathrm{g}^{-1}\right)$ is the dye fraction uptake at time $t, k_{\mathrm{i}}\left(\mathrm{mg} \mathrm{g}^{-1}\right.$ $\left.\min ^{-0.5}\right)$ is the intra-particle diffusion constant, and $C_{\mathrm{i}}\left(\mathrm{mg} \mathrm{g}^{-1}\right)$ is a constant that gives an idea about the thickness of boundary layer. If $C=0$, the intra-particle diffusion is the only rate-limiting step, conversely if $C \neq 0$, the adsorption process is controlled by various adsorption mechanisms. ${ }^{18}$ The plot of $q_{t} v s . t^{0.5}$ is shown in Fig. 9c and the obtained parameters are listed in Table 2. It's assumed that the transport of adsorbate from the solution phase to the surface of the adsorbent particles may be controlled by one or more steps. ${ }^{46}$ In our study, it can be observed from Fig. 9c that there are two steps during the biosorption process of $\mathrm{MB}$ onto extracted CMFs. The initial linear portion with higher slope $\left(k_{\mathrm{i} 1}=\right.$ 12.4) indicates the transport of dye molecules from the solution to the external surface of extracted CMFs by diffusion through boundary layer. ${ }^{45}$ The second linear portion with lower $\left(k_{\mathrm{i} 2}=0.97\right)$ slope is the gradual adsorption stage with intra-particle diffusion dominating. ${ }^{46}$ The MB is first adsorbed by the outer surface of used CMFs, for that the adsorption rate is very high. Once the outer surface is completely saturated, the dye molecule diffuses into the internal pores within the microfibrils network, and is finally adsorbed by the inner surface of the extracted cellulose. When the dye molecules diffuse through the internal pores, the diffusion resistance increases, which results in a decrease in the diffusion rate. As expected, the values of $C$ (Table 2) show that the constants $C$ are not zero in any case. This showed that pore diffusion was not the rate-limiting step. Consequently, the adsorption process may be of a complex nature consisting of both, 

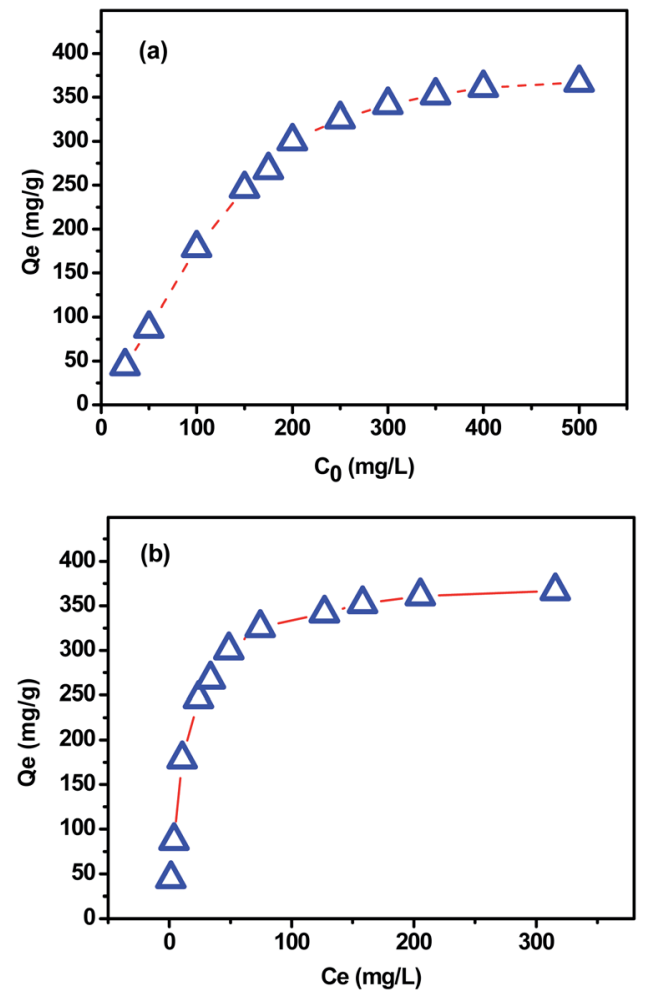

Fig. 10 Adsorption capacity as function of (a) initial and (b) equilibrium MB concentration.

surface adsorption and intra-particle diffusion. ${ }^{46}$ Furthermore, as can be seen in Table 2, the value of $R^{2}$ in first adsorption step is larger than that in second step while $C_{1}$ was smaller than $C_{2}$. This shows that the intra-particle diffusion can predict the kinetic process at different stages. ${ }^{46}$

\section{Effect of dye concentration and adsorption isotherms}

The dye concentration in solution can strongly affect the sorption process. The effect of this parameter on MB removal by using the extracted CMFs was investigated. Fig. 10 represents the adsorption capacity $\left(q_{\mathrm{e}}\right)$ as function of initial $\left(C_{0}\right)$ and equilibrium $\left(C_{\mathrm{e}}\right) \mathrm{MB}$ concentration measured at the equilibrium contact time of $150 \mathrm{~min}$. From these obtained results, it was found that when the initial dye concentration increased from 25 to $500 \mathrm{mg} \mathrm{L}^{-1}$, the adsorbent amount of MB increased from 60 to $380 \mathrm{mg} \mathrm{g}^{-1}$. This behavior is due to the fact that the initial dye concentration provides a powerful driving force to overcome the mass transfer resistance between the aqueous and solid phases. ${ }^{46}$ Beyond the initial concentration of about $300 \mathrm{mg} \mathrm{L}^{-1}$, the adsorption kept nearly constant owing to the saturation of the active sites of extracted CMFs. ${ }^{47}$

In order to determine the parameters associated with $\mathrm{MB}$ adsorption, the experimental data were modeled with the three most commonly used isotherm models namely Langmuir, Freundlich and Temkin.

The Langmuir isotherm model (eqn (8)) assumes that the adsorption is monolayer onto identical active sites of adsorbent with uniform adsorption energies and without lateral interaction and steric hindrance between the adsorbed molecules. ${ }^{48}$ It can be expressed in the linear form as:

$$
\frac{C_{\mathrm{e}}}{q_{\mathrm{e}}}=\frac{1}{k_{\mathrm{L}} q_{\mathrm{m}}}+\frac{1}{q_{\mathrm{m}}} C_{\mathrm{e}}
$$

where $C_{\mathrm{e}}\left(\mathrm{mg} \mathrm{L}^{-1}\right)$ is the equilibrium concentration of $\mathrm{MB}, q_{\mathrm{e}}$ $\left(\mathrm{mg} \mathrm{g}^{-1}\right)$ and $q_{\max }\left(\mathrm{mg} \mathrm{g}^{-1}\right)$ the equilibrium and maximum
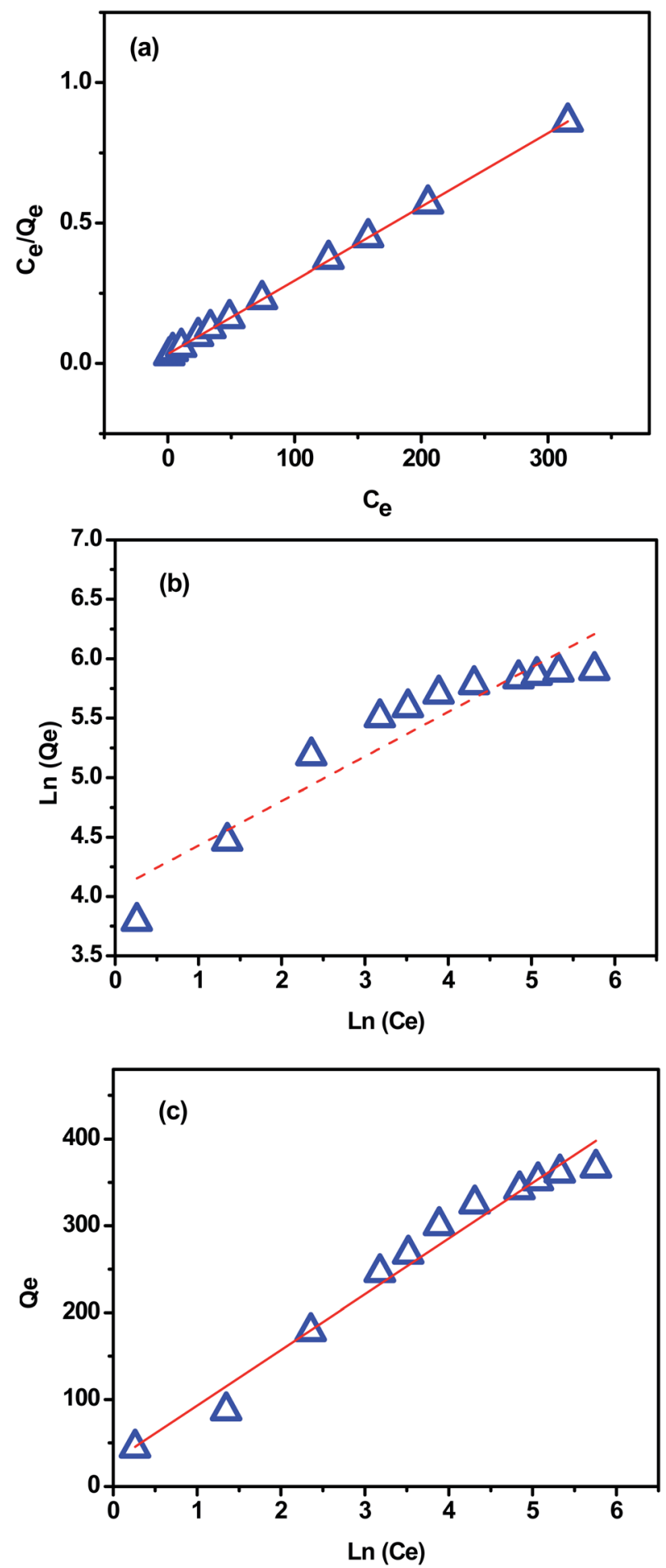

Fig. 11 (a) Langmuir isotherm, (b) Freundlich isotherm and (c) Temkin isotherm. 
a promising low-cost adsorbent for efficient recovery of cationic dyes from aqueous solutions.

\section{Conclusion}

This study has demonstrated that new cellulose microfibrils (CMFs) with tendril helical morphology and highly hydrated gel-like behavior can be extracted from cocoa bean shells waste, using simple chemical treatments. It was found that the asextracted CMFs gel can easily be transformed into powdered form via freeze drying process or in form of stable film using the casting process followed by air drying. Morphological analysis demonstrated that the as-extracted CMFs exhibit a mixture of linear long microfibrils, with an average diameter of $1 \mu \mathrm{m}$, and tendril helical microfibrils with an average diameter of $10 \mu \mathrm{m}$, forming an entangled network gel at its hydrated form. Structural analysis confirmed that CMFs have the same cellulose crystalline form and its structure is comparable to the commercial available microcrystalline cellulose. This study reveals that the as-extracted CMFs have a potential to be used as efficient adsorbent for the removal of different cationic dyes from industrial wastewater. The high swelling capacity of CMFs (190\%) and its special morphology were found to be effective for enhancing its adsorption capacity. By using methylene blue as cationic dye, batch studies illustrated that the kinetics of the dye adsorption process was well fitted with the pseudo-secondorder kinetic model, and the adsorption isotherms can be also described well by the Langmuir isotherm model with a maximum adsorption capacity of $381 \mathrm{mg} \mathrm{g}^{-1}$. The extraction of CMFs, with specific morphology and properties, from cocoa bean shells waste would not only help to reduce the costs of the production of cocoa products but would also manage the disposal of this waste in an environmental friendly manner through the production of new added value materials. This study will allow us to continue valorizing this waste in order to produce new value-added materials for advanced application, such as biomaterials for food packaging.

\section{Conflicts of interest}

There are no conflicts to declare.

\section{Acknowledgements}

The financial assistance of the Office Chérifien des Phosphates (OCP S.A.) in the Moroccan Kingdom toward this research is hereby acknowledged. This work was performed as part of collaboration between the INRA (UMR-IATE, Montpellier, France) and the Materials Science and Nanoengineering Department (MSN) of the Mohamed 6 Polytechnic University (UM6P) in Morocco. The authors would like to thank Dr A. Barakat and B. M. Ruesgas Ramón from INRA-UMR-IATE for their help to improve this work, and Dr Mirna Leonor Suárez Quiroz and Dr Oscar González Ríos from the Instituto Tecnológico de Veracruz (Veracruz, Mexico) for supplying the original CBS.

\section{Notes and references}

1 S. Kalia, A. Dufresne, B. M. Cherian, B. S. Kaith, L. Avérous, J. Njuguna and E. Nassiopoulos, Int. J. Polym. Sci., 2011, 2011, 1-35.

2 Y. Habibi, L. A. Lucia and O. J. Rojas, Chem. Rev., 2010, 110, 3479-3500.

3 O. Nechyporchuk, M. N. Belgacem and J. Bras, Ind. Crops Prod., 2016, 93, 2-25.

4 R. J. Moon, A. Martini, J. Nairn, J. Simonsen and J. Youngblood, Chem. Soc. Rev., 2011, 40, 3941-3994.

5 M. Prakash Menon, R. Selvakumar, P. Suresh kumar and S. Ramakrishna, RSC Adv., 2017, 7, 42750-42773.

6 S. Y. Ding, S. Zhao and Y. Zeng, Cellulose, 2014, 21, 863-871. 7 D. Trache, M. H. Hussin, C. T. Hui Chuin, S. Sabar, M. R. N. Fazita, O. F. A. Taiwo, T. M. Hassan and M. K. M. Haafiz, Int. J. Biol. Macromol., 2016, 93, 789-804.

8 D. R. Smyth, Development, 2016, 143, 3272-3282.

9 J.-S. Wang, G. Wang, X.-Q. Feng, T. Kitamura, Y.-L. Kang, S.-W. Yu and Q.-H. Qin, Sci. Rep., 2013, 3, 3102-3108.

10 D. C. G. Okiyama, S. L. B. Navarro and C. E. C. Rodrigues, Trends Food Sci. Technol., 2017, 63, 103-112.

11 FAO, FAOSTAT, http://www.fao.org/faostat.

12 I. A. Emiola, O. O. Ojebiyi and T. O. Akande, Int. J. Poult. Sci., 2011, 10, 987-990.

13 G. Mancini, S. Papirio, P. N. L. Lens and G. Esposito, Environ. Eng. Sci., 2016, 33, 843-850.

14 F. Fioresi, J. Vieillard, R. Bargougui, N. Bouazizi, P. N. Fotsing, E. D. Woumfo, N. Brun, N. Mofaddel and F. Le Derf, J. Colloid Interface Sci., 2017, 494, 92-97.

15 A. W. Carpenter, C. F. De Lannoy and M. R. Wiesner, Environ. Sci. Technol., 2015, 49, 5277-5287.

16 C. H. Chan, C. H. Chia, S. Zakaria, M. S. Sajab and S. X. Chin, RSC Adv., 2015, 5, 18204-18212.

17 Y. Zhou, M. Zhang, X. Wang, Q. Huang, Y. Min, T. Ma and J. Niu, Ind. Eng. Chem. Res., 2014, 53, 5498-5506.

18 H. Shi, W. Li, L. Zhong and C. Xu, Ind. Eng. Chem. Res., 2014, 53, 1108-1118.

19 L. Jin, W. Li, Q. Xu and Q. Sun, Cellulose, 2015, 22, 24432456.

20 H. Qiao, Y. Zhou, F. Yu, E. Wang, Y. Min, Q. Huang, L. Pang and T. Ma, Chemosphere, 2015, 141, 297-303.

21 D. Trache, A. Donnot, K. Khimeche, R. Benelmir and N. Brosse, Carbohydr. Polym., 2014, 104, 223-230.

22 H. Y. Yu, D. Z. Zhang, F. F. Lu and J. Yao, ACS Sustainable Chem. Eng., 2016, 4, 2632-2643.

23 M. H. Hussin, N. A. Pohan, Z. N. Garba, M. J. Kassim, A. A. Rahim, N. Brosse, M. Yemloul, M. R. N. Fazita and M. K. M. Haafiz, Int. J. Biol. Macromol., 2016, 92, 11-19.

24 R. Batmaz, N. Mohammed, M. Zaman, G. Minhas, R. M. Berry and K. C. Tam, Cellulose, 2014, 21, 1655-1665.

25 N. Ben Douissa, L. Bergaoui, S. Mansouri, R. Khiari and M. F. Mhenni, Ind. Crops Prod., 2013, 45, 106-113.

26 N. El Miri, K. Abdelouahdi, M. Zahouily, A. Fihri, A. Barakat, A. Solhy and M. El Achaby, J. Appl. Polym. Sci., 2015, 132, 42004, DOI: 10.1002/app.42004. 
27 M. El Achaby, N. El Miri, A. Aboulkas, M. Zahouily, E. Bilal, A. Barakat and A. Solhy, Int. J. Biol. Macromol., 2017, 96, 340352.

28 M. El Achaby, Z. Kassab, A. Aboulkas, C. Gaillard and A. Barakat, Int. J. Biol. Macromol., 2018, 106 , 681-691.

29 C. S. Julie Chandra, N. George and S. K. Narayanankutty, Carbohydr. Polym., 2016, 142, 158-166.

30 S. Gea, C. T. Reynolds, N. Roohpour, B. Wirjosentono, N. Soykeabkaew, E. Bilotti and T. Peijs, Bioresour. Technol., 2011, 102, 9105-9110.

31 P. Lopez-Sanchez, M. Rincon, D. Wang, S. Brulhart, J. R. Stokes and M. J. Gidley, Biomacromolecules, 2014, 15, 2274-2284.

32 Q. Wang, J. Cai, L. Zhang, M. Xu, H. Cheng, C. C. Han, S. Kuga, J. Xiao, R. Xiao, S. Renneckar, C. Han and S. Kuga, J. Mater. Chem. A, 2013, 1, 6678-6686.

33 J. O. Zoppe, V. Ruottinen, J. Ruotsalainen, S. Rönkkö, L. S. Johansson, A. Hinkkanen, K. Järvinen and J. Seppälä, Biomacromolecules, 2014, 15, 1534-1542.

34 C. J. Chirayil, J. Joy, L. Mathew, M. Mozetic, J. Koetz and S. Thomas, Ind. Crops Prod., 2014, 59, 27-34.

35 M. Jonoobi, J. Harun, P. M. Tahir, A. Shakeri, S. Saifulazry and M. D. Makinejad, Mater. Lett., 2011, 65, 1098-1100.

36 R. M. Sheltami, I. Abdullah, I. Ahmad, A. Dufresne and H. Kargarzadeh, Carbohydr. Polym., 2012, 88, 772-779.

37 W. P. Flauzino Neto, H. A. Silvério, N. O. Dantas and D. Pasquini, Ind. Crops Prod., 2013, 42, 480-488.

38 A. Dmytryk, A. Saeid and K. Chojnacka, Sci. World J., 2014, 2014, 356328, DOI: $10.1155 / 2014 / 356328$.

39 Y. C. Ching and T. S. Ng, BioResources, 2014, 9, 6373-6385.
40 X. Y. Tan, S. B. Abd Hamid and C. W. Lai, Biomass Bioenergy, 2015, 81, 584-591.

41 N. Kasyapi, V. Chaudhary and A. K. Bhowmick, Carbohydr. Polym., 2013, 92, 1116-1123.

42 S. M. Luz, J. Del Tio, G. J. M. Rocha, A. R. Gonçalves and A. P. Del'Arco, Composites, Part A, 2008, 39, 1362-1369.

43 W. H. Chen, Y. J. Tu and H. K. Sheen, Appl. Energy, 2011, 88, 2726-2734.

44 C. Kannan, N. Buvaneswari and T. Palvannan, Desalination, 2009, 249, 1132-1138.

45 C. Zhou, Q. Wu, T. Lei and I. I. Negulescu, Chem. Eng. J., 2014, 251, 17-24.

46 N. Fayoud, S. Tahiri, S. Alami Younssi, A. Albizane, D. Gallart-Mateu, M. L. Cervera and M. de la Guardia, Desalin. Water Treat., 2016, 57, 16611-16625.

47 T. Benhalima, H. Ferfera-Harrar and D. Lerari, Int. J. Biol. Macromol., 2017, 105, 1025-1042.

48 M. Baghdadi, A. Jafari and A. Pardakhti, RSC Adv., 2016, 6, 61423-61433.

49 X. Yang, H. Liu, F. Han, S. Jiang, L. Liu and Z. Xia, Carbohydr. Polym., 2017, 175, 464-472.

50 S. P. Santoso, L. Laysandra, J. N. Putro, J. Lie, F. E. Soetaredjo, S. Ismadji, A. Ayucitra and Y. H. Ju, J. Mol. Liq., 2017, 233, 29-37.

51 X. Y. He, K. B. Male, P. N. Nesterenko, D. Brabazon, B. Paull and J. H. T. Luong, ACS Appl. Mater. Interfaces, 2013, 5, 87968804.

52 J. Tao, J. Xiong, C. Jiao, D. Zhang, H. Lin and Y. Chen, Carbohydr. Polym., 2017, 166, 271-280.

53 S. Hokkanen, A. Bhatnagar and M. Sillanpää, Water Res., 2016, 91, 156-173. 